\title{
21 Bereavement After Suicide: a Study of Memorials on the Internet ${ }^{73}$
}

When a person dies, those close to the deceased typically experience great sorrow, but the precise nature of the emotions experienced probably depends upon the cause of death. A death which is sudden and unexpected may have different consequences for the survivors than a death which was anticipated and for which the survivors had time to prepare. Even for unexpected deaths, the nature of the death may have an impact. Death from murder may leave survivors with different emotions than death from suicide or a heart attack. The other chapters in this book have attempted to understand the mind of the suicidal individual, but the present chapter explores the way in which the bereaved write about the suicide.

Death from suicide may result in a complex and intense set of emotional responses, including sadness, grief and anguish, as well as anger and guilt. Other emotions are aroused by the stigma that society attaches to suicide. The suicide of a person suggests the presence of psychiatric disorder in the deceased, and this leads to the suspicion that the whole family is psychiatrically disturbed. If the suicide was a respected and admired person in the community, friends may wonder what the relatives of the suicide did which drove the individual to take his own life.

To explore these issues, research into the aftermath of suicide has taken two separate approaches. The first strategy has been to ask the survivors of a suicide about their experiences, while the second strategy has been to ask members of the general public how they would view the survivors of a suicide. The first strategy focuses on the bereavement experience of the survivors of the suicide, while the second strategy focuses on the stigma that the survivors may have to face.

As Rudestam (1990) has pointed out, it is critically important to include an appropriate comparison group in studies of the bereaved survivors of a suicide. It is obvious that the survivors of a suicide will experience psychological and physical dysfunctions as part of the grief process. The crucial question, however, is whether these experiences differ from the grief process after a nonsuicidal death.

In addition, suicide may lead to reactions because the death was violent, guilt because the survivors feel they ought to have somehow intervened and prevented the suicide, and anger at the suicide for choosing to die in that particular manner. A suicidal death also has an effect on the mourning rituals, such as the funeral and religious services, and may lead to withdrawal of support from social networks because of the discomfort felt by neighbors and friends. Finally, the occurrence of a suicide suggests that the family system was dysfunctional already, and a dysfunctional

73 This chapter is based on Lester (2012).

(c)) BY-NC-ND (C) 2014 David Lester.

This work is licensed under the Creative Commons Attribution-NonCommercial-NoDerivs 3.0 License 
family may have more difficulty in coming to terms with the death of a family member.

In a novel approach to this issue, Calhoun, Selby, and Steelman (1988-1989) asked funeral directors whether the mourners of a suicide differ from those of a natural death. Two main themes emerged. Family members of a suicide seemed to experience greater shock and more difficulty in dealing with the death, and the suicidal deaths seemed to generate more questioning in the mourners. The funeral directors themselves felt more constrained in dealing with the family of a suicide and had more difficulty in expressing sympathy and knowing what to say or do.

In studies of the emotional reactions of the bereaved, Rudestam (1977), for example, has documented relief, anger and depression in survivors of suicides, but research on those losing loved ones from other causes have shown that these emotions occur equally often in those individuals too (Calhoun, Selby, \& Selby, 1982). The guilt experienced, however, does seem to be stronger in the survivors of a suicide (Glick, Weiss, \& Parkes, 1974). Cognitive reactions in the survivors of suicide include shock and disbelief, a search for explanations, and denial. Studies which have included a comparison group have indicated that the search for explanations is more intense if the deceased was a suicide and less easily resolved (Sheskin \& Wallace, 1976).

The circumstances of the suicide have been found to affect the resolution of these reactions. For example, Rudestam (1977) found that family members who discovered the body of the suicide were slower in recovering. The suicide can also make the resolution of grief difficult by the way he kills himself. For example, a person who shoots himself in the head, thereby disfiguring himself, in a locale where a loved one will discover his body, is clearly expressing anger toward the survivor. Discovering the deceased will be especially traumatic for the survivors.

Recent research continues to find differences in grief after a suicide versus other causes of death. For example, do Groot, de Keijser, and Neeleman (2006) found that survivors who had lost a relative to suicide, as compared to those who had lost a relative from natural causes, had higher scores on measures of neuroticism, loneliness, depression and complicated grief, lower scores on measure of general health and expressed more a need for professional help three months after the death. Harwood, Hawton, Hope, and Jacoby (2002) found that survivors of suicide, as compared to survivors of natural deaths, felt more stigmatization, shame and a sense of rejection.

Mitchell, Kim, Prigerson, and Mortimer-Stephens (2004) found that survivors who lost a closely related person to suicide versus those who were only distantly related were significantly more likely to meet the criteria for complicated grief, a syndrome involving intrusive and distressing symptoms and symptoms of traumatization such as numbness, detachment and excessive anger and bitterness.

The present chapter takes a very different approach from previous research. Whereas previous research has administered questionnaires containing psychological and psychiatric inventories, the present study examined the memorials that 
survivors leave on Internet websites devoted to those grieving. Written memorials on a website for survivors of suicide were compared to those on a website for grief and loss in general using the LIWC.

All 17 memorials posted on the website www.spanusa.org were downloaded. Each was written by a suicide survivor, that is, someone who had lost a significant other to suicide. Fifteen were written by women and two by men. Nine had lost a child, four a sibling, two a spouse, one a parent, and one an employer. Seventeen comparison postings were obtained from www.grieflossrecovery.com. These were consecutive postings after eliminating postings that were about suicide $(n=2)$, not about death $(n=2)$, additional postings from the same person $(n=2)$, in a foreign language $(\mathrm{n}=1)$, and about a dog $(\mathrm{n}=1)$. The 34 postings were run through the LIWC program. Of the 73 comparisons, 13 were statistically significant and a further 13 tended toward statistical significance, many more than would be expected by chance in 73 statistical tests (see Table 21-1).

The postings from survivors of suicide had longer sentences and had a greater proportion of long words. They had fewer references to the deceased, more references to death, but fewer references to religion. They had more references to work, occupation, and school. They tended to have fewer references to the self, more references to anger and sadness, and fewer references to insight and understanding (words such as think, know, and consider).

Several significant differences had psychological relevance. For example, the memorials written by survivors of suicide had more references to death, had longer sentences and may be more complex as indicated by the use of more long words. The deaths from suicide, therefore, seemed to have a more profound impact on the survivors than the natural deaths. There were also more words reflecting anger and sadness, indicating more emotional distress, which is consistent with the research mentioned above which has found that complicated grief is more common to the survivors of suicide.

Finally, there were fewer words concerned with religion in the memorials written by survivors of suicide, suggesting that religion was less of a comfort for survivors of suicide than for survivors of natural deaths. Survivors of suicide are at increased risk of suicide themselves, perhaps because of inherited predispositions to psychiatric illness and the trauma of experience of the loss of a significant other to suicide (Runeson \& Asberg, 2003), and it may be that conventional methods of alleviating the stress of loss, such as religion, are less effective for survivors of suicide. 
Tab. 22.1: A comparison of written memorials from significant others who lost some to suicide versus other causes

\begin{tabular}{|c|c|c|}
\hline & Grief website & Suicide website \\
\hline Words per sentence & 14.8 & $18.6^{\star \star}$ \\
\hline Words longer than 6 letters & 13.8 & $18.6^{\star \star \star}$ \\
\hline Pronouns & 15.9 & $13.1^{\star}$ \\
\hline You & 2.7 & $0.6^{*}$ \\
\hline Negations & 2.0 & $1.1^{\star \star \star}$ \\
\hline Senses & 2.9 & $1.9^{\star \star}$ \\
\hline Seeing & 0.9 & $0.5^{\star}$ \\
\hline Occupations & 1.4 & $2.4^{\star \star}$ \\
\hline School & 0.3 & $0.8^{\star}$ \\
\hline Job & 0.3 & $0.7^{*}$ \\
\hline Religion & 0.6 & $0.2^{\star}$ \\
\hline Death & 0.7 & $1.3^{*}$ \\
\hline Eating & 0.3 & $0.1^{\star}$ \\
\hline Words in the dictionary & 80.4 & $77.7 \#$ \\
\hline First person singular & 6.3 & $4.6 \#$ \\
\hline Total first person & 8.0 & $6.2 \#$ \\
\hline Prepositions & 12.5 & $13.7 \#$ \\
\hline Anger & 0.2 & $0.4 \#$ \\
\hline Sad & 1.0 & $1.4 \#$ \\
\hline Insight & 2.3 & $1.9 \#$ \\
\hline Inhibition & 0.3 & $0.5 \#$ \\
\hline Hearing & 1.2 & $0.8 \#$ \\
\hline Friends & 0.2 & $0.3 \#$ \\
\hline Humans & 0.6 & $0.9 \#$ \\
\hline Time & 5.6 & $4.8 \#$ \\
\hline Music & 0.15 & $0.04 \#$ \\
\hline
\end{tabular}

$\star \star \star *$ two-tailed $p<.001,{ }^{* *}$ two-tailed $p<.01,{ }^{*}$ two-tailed $p<.05, \#$ trend (two-tailed $\left.p<.10\right)$ 